\title{
GAMPI
}

\section{A iluminação pública e sua função nos centros urbanos}

\author{
The street lighting and your office in urban centers
}

ALVES, Diana Felipe; Graduanda em Design; Univille

dianafelipealves@gmail.com.br

SANTOS, Adriane Shibata; Doutora em Design; Univille adriane.shibata@univille.br

\section{Resumo}

Com a descoberta do fogo e seu poder de iluminação, a necessidade de iluminar espaços começou a estar cada vez mais presente no cotidiano das cidades. Uma vez que a iluminação pública trata-se de uma das formas de iluminar mais importantes da atualidade, além de estabelecer relação direta à qualidade de vida da população, essa pesquisa se originou na necessidade de compreender a relação de dependência do bem estar social com a iluminação pública a fim de gerar desenvolver materiais que auxiliem no desenvolvimento de projetos eficientes.

Palavras Chave: iluminação pública; qualidade de vida e cidades inteligentes.

\section{Abstract}

With the discovery of fire and its light power, the need to illuminate places started to become even more present in cities's daily life. Since public lighting is treated as one of the most important lighting ways in modern times, beyond establishing a direct relationship between a population's life quality, this research was originated from the necessity to comprehend the dependence between social well being and public lighting, hoping to create and develop material that will help with more efficient projects.

Keywords: street lighting; quality of life; smart cities.

\section{Introdução}

Sabe-se que o homem percebeu o poder do fogo no período Paleolítico, quando existiu a necessidade de espantar animais e aquecer o ambiente em que viviam (MUSEU DA LÂMPADA, sd, web), sendo assim, indiretamente o ambiente em que habitavam também era iluminado. Já a iluminação de ambientes externos de maneira consciente só passou a existir no antigo Egito (GOITIA, 1995 apud MACEDO, 2002). Jaime Lerner, urbanista e político influente no estado do Paraná, afirma que a cidade é o "principal cenário do encontro das 5o GAMPI Plural, 2015, UNIVILLE, Joinville, SC 


\section{GAMPI plural 15}

pessoas" (2013 apud GEHL, 2013). Dessa maneira, compreende-se que é com base no encontro dos indivíduos que ocorre o desenvolvimento humano, e para que esse encontro ocorra de maneira agradável torna-se necessário a presença de ambientes agradáveis.

Definida pelo Inciso XXXVI do Art. $2^{\circ}$ da Resolução Normativa Aneel 414/2010, a iluminação pública trata-se de um serviço público que deve promover a boa qualidade de vida da população, tendo como função a inibição do crime, promoção do jovem saudável, redução de acidentes de trânsito, atração de turistas e aumento da autoestima dos moradores (SECRETARIA DE ENERGIA - SP, 2013). Ainda que se tenha conhecimento da importância da iluminação pública no bem estar social, poucos projetos tem se voltado para esse fim, sendo que os existentes não contemplam todo seu potencial, dessa maneira, o desenvolvimento de um estudo a respeito da evolução e condição das luminárias urbanas torna-se de grande importância, como é destacado por Kirschbaum (2013, p. 7 apud MASCARÓ, 2006):

[...] considerando o ritmo do crescimento demográfico para os próximos anos, a iluminação urbana é, assim, uma questão tão importante para a qualidade e sustentabilidade da vida de cidades e países.

Diante da importância da iluminação pública no cotidiano das pessoas, este artigo tem por objetivo apresentar alguns estudos e levantamentos desenvolvidos em um projeto de pesquisa desenvolvido por uma das autoras desse artigo, sendo que este buscava desenvolver um levantamento histórico da iluminação pública, compreender seus conceitos e sua relação com o bem estar social.

\section{Primeiro contato com a iluminação pública}

Com a descoberta do fogo, os hominídeos também puderam perceber que este apresentava poder de afugentar animais, cozer alimentos e iluminar ambientes (SOUSA, sd, web). Compreendendo o poder de iluminar do fogo, o homem passou a buscar maneiras de transporta-lo para outros locais, por meio de tochas. Para Oliveira (2010, web) a iluminação por meio do fogo transmitia segurança aos hominídeos nos períodos noturnos, possibilitando maior tempo de reflexão sobre os acontecimentos que ocorriam durante o dia. Porém o uso 


\section{GAMPI}

consciente da luz artificial para iluminar ambientes externos tem seus primeiros registros no Império Romano, quando era utilizada em eventos especiais, iluminando o caminho das carruagens (MASCARÓ, 2006). Contudo, o processo de utilizar luz para iluminar vias públicas teve seu provável início em 1415, na Inglaterra, quando os comerciantes começaram a exigir uma forma de combater os crimes que os assombravam (Eletrobrás Procel, 2013).

A iluminação pública (IP) existiu de forma muito precária até o século XVII, quando a população começou a exigir uma melhor maneira de iluminar já existentes, quando trazendo diversos inventos à humanidade (MASCARÓ, 2006). Com a inserção de IP no cenário urbano, percebeu-se o aumento do número de pessoas circulando pelas ruas em horários noturnos, alterando até mesmo as atividades comerciais, já que a IP proporcionou uma sensação de segurança não existente anteriormente (ROSITO, 2009). Com isso, é possível afirmar que a IP pôde transformar os hábitos e o modo de viver da sociedade.

Conforme Ferreira (2009), acredita-se que no Brasil, a preocupação com processos de iluminação só começou a ser desenvolvida com a chegada das caravelas, uma vez que os nativos utilizavam sua criatividade para desenvolver utensílios para usufruir da fartura de água e alimentos existente. Foi no século XVIII, com a instalação no Brasil de um centro de conhecimentos tecnológicos, que deu-se início à expansão dos empreendimentos ligados ao uso do poder de iluminação da gordura animal no país (idem). Diante desse fato, acredita-se que em 1794, iniciou-se a utilização de iluminação pública no Rio de Janeiro, quando 100 luminárias de azeite foram instaladas no centro da cidade (Eletrobrás Procel, 2013). Ferreira (2009, p. 5) apresenta um levantamento histórico da condição evolutiva da iluminação pública na cidade do Rio de Janeiro e aponta as condições de instalação que estas possuíam:

\footnotetext{
Poucos documentos existem desses primeiros tempos [...] lanternas, como eram estão chamadas ao luminárias de iluminação externa [...] Elas iluminavam a entrada de edifícios públicos e de residências de pessoas de maiores recursos, instaladas ao lado das ombreiras das portas. [...] A iluminação das vias públicas limitava-se [...] como referência para o logradouro do que a um propósito de iluminação.
}

Conforme colocado pelo autor, pouco conhecimento e registros se têm sobre a condição da iluminação pública em seu início histórico, mas acredita-se que por volta de 1790 


\section{GAMPI plural 15}

"as casas eram iluminadas por meio de pequenos cilindros coloridos de vidro, enchidos com cera e com um pavio no centro" (ibidem, 2013).

Quando, em 1808 a família real mudou-se para o Brasil, desenvolveu-se a necessidade de apresentar soluções para a criminalidade presente da época, sendo assim, providenciou-se a instalação de luminárias a fim de diminuir a escuridão dos becos e vielas, onde multiplicavam-se os marginais (SANTANA, 2010).

Nesse momento, a cada 100 metros foram instalados lampiões fixados em colunas de pedra e cal, postes, nas principais ruas, sendo estas acendidas com o uso de óleos proveniente de baleias, cocos e mamonas, através de lampiões escravos (idem, 2013). A figura 1 apresenta a representação de Debret (1820) sobre a realidade dos escravos abastecendo os lampiões.

Figura 1 - Iluminação a azeite - Tela de Debret

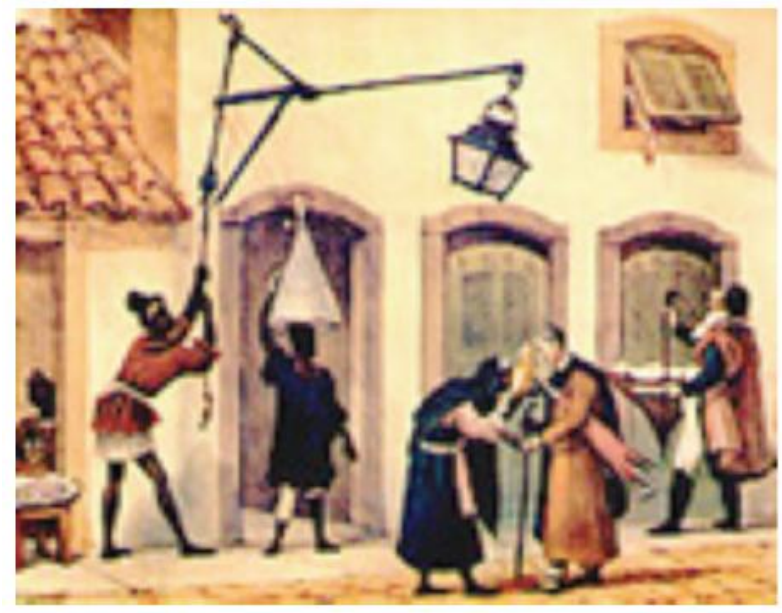

Fonte: Debret (1820 apud FERREIRA, 2009)

Foi no séc. XVII que iniciaram os estudos de novas fontes de energia, tendo em 1875 a primeira lâmpada de arco voltaico desenvolvida por Paul Jablochkoff, utilizada na IP até as primeiras décadas do século XX, e em 1879 Thomas Edison apresentou a lâmpada incandescente, o que deu início aos estudos de substituição (FERREIRA, 2009). No Brasil, em 1889, o presidente Campo Sales autorizou que a empresa Light instalasse em São Paulo e no Rio de Janeiro energia elétrica na iluminação pública (MARTINS, 2011, web), sendo que com a implementação da Light no contexto brasileiro diversos avanços ocorreram, alterando a eficiência das luminárias públicas e do potencial energético do país. A figura 2 abaixo, 5o GAMPI Plural, 2015, UNIVILLE, Joinville, SC 


\section{GAMPI
plural ${ }^{15}$}

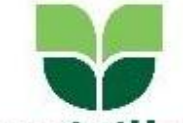

univille

apresenta dois tipos de luminárias urbanas, ao centro da avenida e as de passeios públicos, presentes em 1905 na área central do Rio de Janeiro:

Figura 2 - Iluminação pública da Avenida Central, Rio de Janeiro, 1905

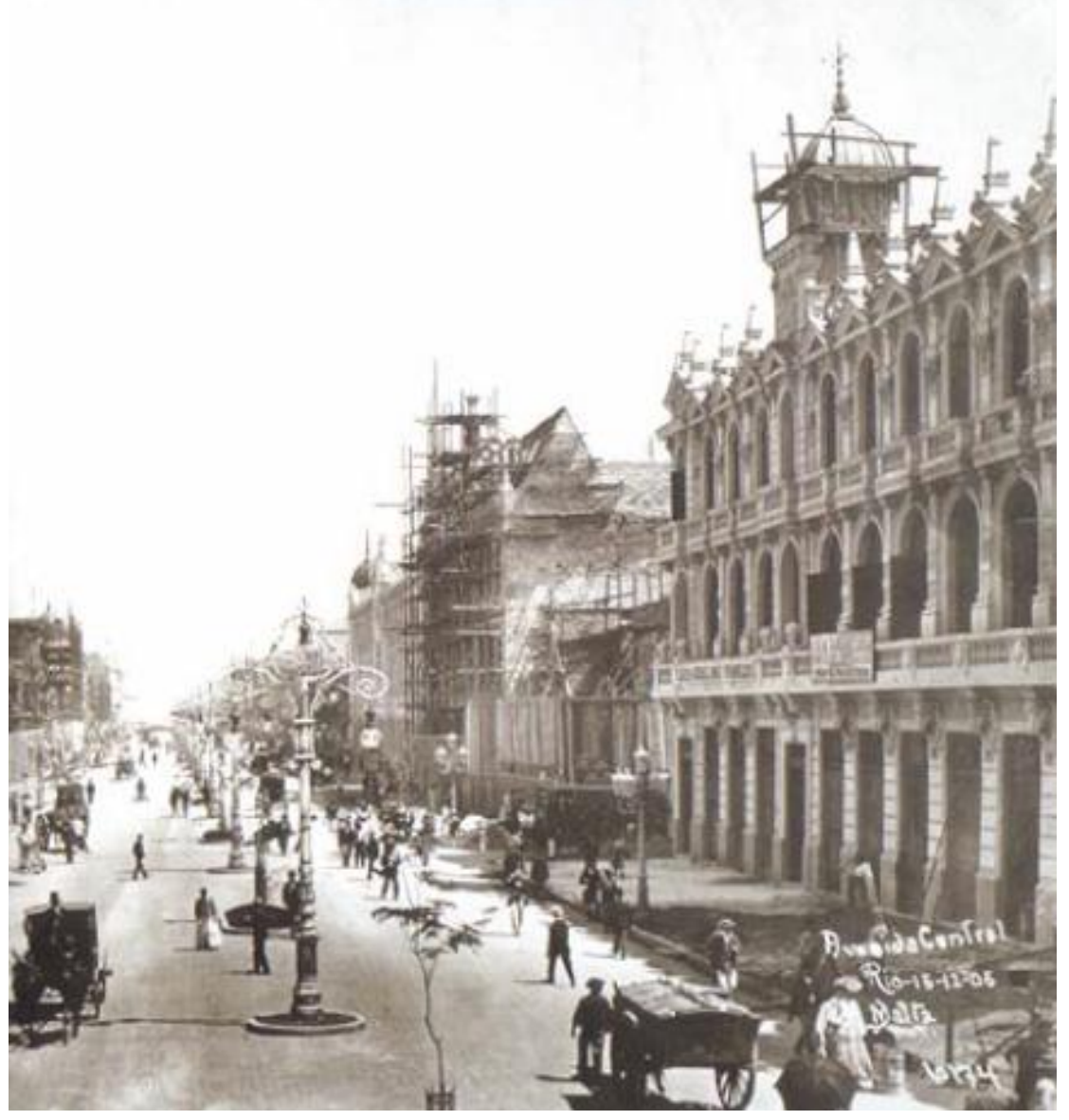

Fonte: MALTA et al, 1997, p.97 apud SANTOS, 2005

Nas calçadas eram utilizadas iluminação a gás e ao centro das vias a iluminação elétrica, além das luminárias bem ornamentadas, de formas variadas, remetiam à urbanização da época (SANTOS, 2005).

Em 1985 o Governo Federal Brasileiro lançou o Programa Nacional de Conservação de Energia, o PROCEL, que remetiam a iluminação pública por meio do Programa Reluz, auxiliando as prefeituras nos planejamentos relacionados à iluminação pública, remodelamento os sistemas e nos ganhos energéticos, econômicos e sociais (Eletrobrás Procel, 2013). 


\section{GAMPI
plural ${ }^{15}$}

É possível perceber que, ainda que com um certo atraso, a IP buscou acompanhar os avanços da sociedade, seguindo as necessidades geradas em cada geração. Com a chegada da energia elétrica, os avanços nas tecnologias das lâmpadas foram contínuos, tanto as de uso público quanto residencial. Com a compreensão da evolução histórica da iluminação pública, é possível perceber que desde o início a IP apresentou impacto direto das relações sociais, sempre estimulando o convívio e melhor aproveitamento do dia.

\section{Função da Iluminação nos centros urbanos}

Compreende-se por iluminação pública àquela que ilumina ambientes externos, sendo classificada como rodoviária, urbana ou monumental. Destas, a que se tem maior compreensão é a urbana, definido como aquela responsável por iluminar as ruas (Eletrobrás Procel, 2013). Atualmente iluminar vias públicas é visto com normalidade, porém, no início desse avanço a população acreditava que elas poderiam trazer doenças, sendo necessária a prática de uma desconstrução dessa ideia pelo governo (Martins, 2011, web).

Ao pensar na função das luminárias públicas, essas devem se adaptar ao que é pretendido iluminar. Deve facilitar a orientação dos pedestres, visualização de pessoas, obstáculos e sinalização, além de auxiliar os motoristas na visualização das calçadas, veículos, pedestres e obstáculos em tempo suficiente para reagir (CANDURA et al, 2009). O autor ainda indica que o atual conceito de IP amplia a visão sobre sua necessidade no meio urbano, apontando que seu funcionamento deve propiciar maior visualização, garantir segurança aos transportes e ao tráfego de veículos, facilitar a orientação do tráfego urbano, realçar a magnitude econômica e cultural da cidade, valorizar patrimônios históricos urbanos, ser confortável visualmente, desestimular a criminalidade e o vandalismo.

Um dos principais problemas que cercam o sistema de iluminação pública é a poluição luminosa, fenômeno que corresponde ao excesso de luz artificial emitida diretamente para o céu através de luminárias que iluminam para cima ou para os lados (LUXSide, 2012, web). Dessa maneira, Mascaró (2009) aponta que cerca de 20\% da luz emitida se perde por falta de controle da IP. A poluição luminosa apresenta diversos impactos na população, estes não se resumindo ao desperdiço e valor da energia elétrica. Um levantamento desenvolvido pelo 


\section{GAMPI}

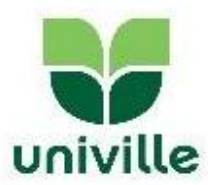

Laboratório Nacional de Astrofísica (LNA), aponta que a poluição luminosa pode afetar o ciclo migratório, alimentar e reprodutivo dos animais, além de alterar o período de floração das plantas; Quando se é levantado os impactos que a poluição luminosa pode gerar nas pessoas, aponta-se que esta pode auxiliar no crescimento de tumores, além de inibir a produção de melatonina, hormônio relacionado ao desenvolvimento de câncer de mama. Nesse sentido, um estudo apresentado pela Chronobiology International (apud FERNANDES et al, sd, web) comparou 147 comunidades israelenses com registros de câncer de mama; os resultados apontaram um aumento significativos de câncer nas comunidades com maior índice de poluição luminosa. Sobre à poluição luminosa, o LNA apresenta um estudo com a maneira mais adequada que uma luminária pública deve iluminar, conforme a figura 3:

Figura 3 - Simulação de direcionamento da luz artificial de luminárias externas

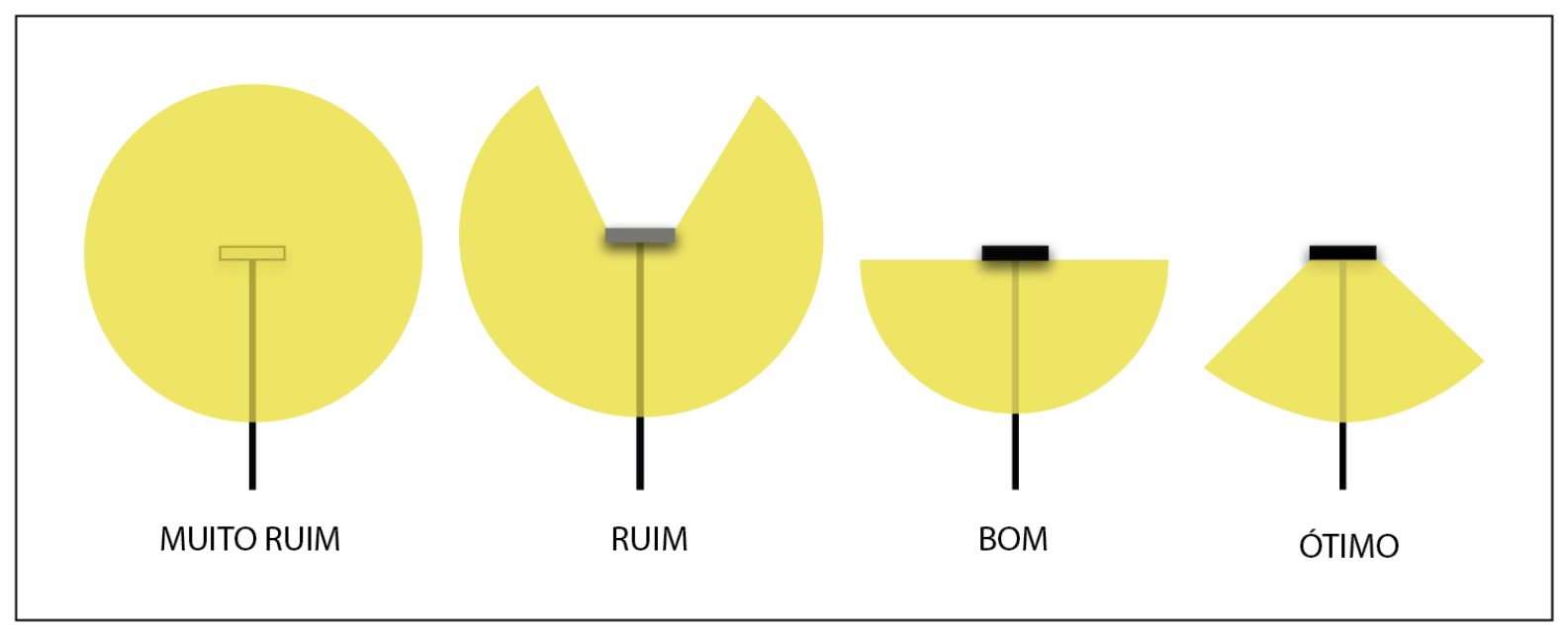

Fonte: Adaptado pela autora com base na imagem desenvolvida pelo Laboratório Nacional de Astrofísica, sd, web.

A figura mostra que a iluminação correta corresponde àquela que ilumina apenas o que precisa ser iluminado, não havendo desperdício de energia para outras áreas. Sendo assim, sabe-se que a iluminação pública têm impacto direto ao bem estar social da comunidade, podendo alterar o funcionamento do sistema endócrino animal e humano, desenvolvendo graves distúrbios à saúde.

Ainda que exista a preocupação com a questão da poluição luminosa, é notória a importância da iluminação urbana para o bom andamento das cidades. Entre as funções da IP já apresentadas anteriormente, destaca-se o desestímulo ao vandalismo e a criminalidade, 5o GAMPI Plural, 2015, UNIVILLE, Joinville, SC 


\section{GAMPI}

sendo esta a grande impulsionadora para o desenvolvimento da iluminação na cidade ao longo dos anos. Esse fenômeno pôde ser observado em 1974 na Inglaterra, durante a crise do petróleo, quando foi reduzido $50 \%$ da iluminação pública de algumas áreas e em paralelo observou-se um amento de $100 \%$ no índice de furtos e $50 \%$ no índice de criminalidade (AVER, 2013). Quando as prefeituras percebem o sentimento de insegurança por parte da população uma das primeiras medidas a serem tomadas é observar os sistemas de iluminação da cidade e as melhorias que podem ser aplicadas, conforme apresentado pelo Sr. Glaucus Foster, Gerente da Unidade Transportes e Vias Públicas da cidade de Joinville (2015). Isso vem de acordo com o que Isac Roizenblatt, diretor técnico da Associação Brasileira da Indústria de Iluminação (Abilux) comenta: "Quem procura fazer algo de errado, não quer ser visto. Por isso, a boa iluminação é uma grande inimiga do crime. Isso está provado mundialmente" (apud AVER, 2013).

Isto posto, percebe-se que a iluminação pública por sua natureza já apresenta diversas funcionalidades, todas de enorme importância para o andamento harmônico da evolução da cidade.

\section{Análise das luminárias públicas das praças de Joinville}

Diante da realidade de que o principal cenário de estudo desse projeto encontra-se na cidade de Joinville, Santa Catarina, foram selecionadas algumas praças e parques para realizar observações de campo na cidade, a fim de relacionar as percepções obtidas nesses ambientes com a situação desse mesmos ambientes à alguns anos atrás. Estes estudos visaram identificar as luminárias utilizadas nesses espaços e as características presentes em cada um deles. Foram observadas duas praças localizadas no centro da cidade, um parque localizado na fronteira de três bairros (Guanabara, Boa Vista e Fátima) e um localizado no bairro Adhemar Garcia, conforme pode ser observado nos itens abaixo:

a) Localizada em uma das áreas mais conhecidas da cidade, entre as ruas do Príncipe, São Joaquim e Luiz Niemeyer, a Praça Nereu Ramos está na região central da cidade desde a década de 1940 (Nossa Joinville, sd, web). Marcada pelas apresentações do Festival de Dança de Joinville e por ser um ponto de encontro de 


\section{GAMPI
plural ${ }^{15}$}

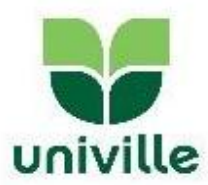

senhores aposentados que diariamente jogam dominó, a praça se caracteriza pela convivência da comunidade naquele espaço. Atualmente a praça encontra-se em boas condições e com iluminação suficiente, porém, apresenta uma atmosfera um pouco sombria nos períodos noturnos, devido às ruas que as circundam possuírem pouca iluminação. No ambiente encontram-se principalmente luminárias em formato de cone invertido, na cor verde escura, alimentada pela rede de distribuição elétrica subterrânea, não havendo poluição da paisagem por cabos de energia. Além destas luminárias, encontra-se um segundo modelo de fixação em postes de concreto, encontradas voltadas para as ruas que cercam a praça. $\mathrm{Na}$ figura 4 é possível observar a comparação entre a realidade da Praça Nereu Ramos em 1930 e atualmente, ficando evidente a diminuição de áreas verdes e o aumento da área de circulação de pedestres.

Figura 4: Comparativo entre a Nereu Ramos de 1930 e 2015 - Joinville/SC

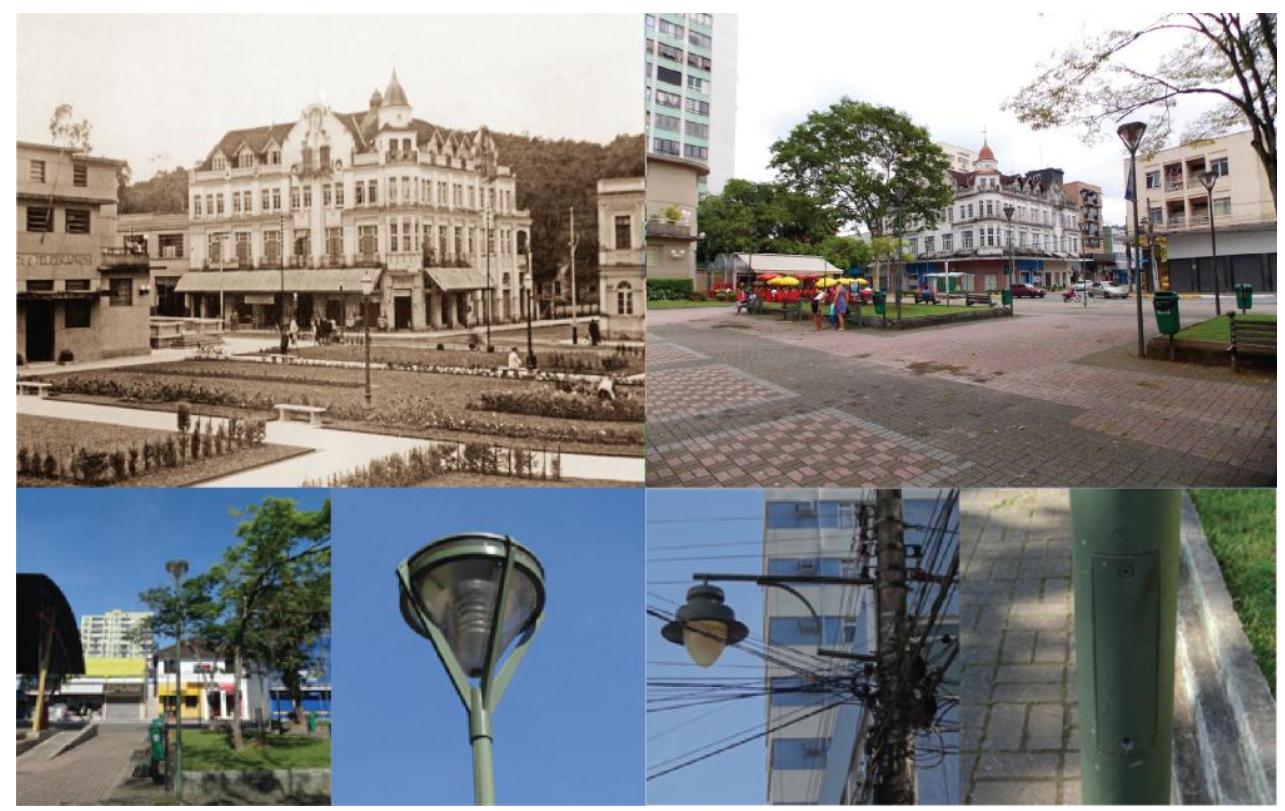

Fonte: Desenvolvido pela autora com base em arquivo pessoal.

b) Construída no século XIX, a Praça Lauro Muller foi instalada com o objetivo de embelezar a cidade e trazer uma área de convívio à população da época (LIMA, 2014). Localizada entre as ruas São Francisco, Comandante Eugênio Lepper, Nove 


\section{GAMPI
plural ${ }^{15}$}

de Março e Luiz Neimeyer, a praça encontra-se como "vizinha" da praça Nereu Ramos. Atualmente é popularmente conhecida como a "Praça da Biblioteca Pública”, porém, foi apenas em 1951, na comemoração dos 100 anos da cidade, que a praça recebeu a instalação da Biblioteca Pública Municipal, mudando o perfil das pessoas que por ali circulavam. Hoje a praça se caracteriza pelo comércio de artesãos ambulantes, transeuntes descansando sob às sombras das árvores e recreação infantil. $\mathrm{O}$ ambiente possui iluminação adequada, existindo uniformidade formal entre as luminárias públicas uma vez que apresenta-se apenas um único modelo de luminária. As luminárias encontradas são na cor verde escura, rede de distribuição elétrica subterrânea e remetem a uma pessoa utilizando um chapéu, sendo um modelo pouco visto em outras áreas da cidade. Ainda que bem iluminada, no período noturno a praça apresenta uma atmosfera sombria, devido a arborização e as luminárias públicas ali encontradas não emitirem luz para às copas das árvores, gerando grandes sombras. Assim como na Praça Nereu Ramos, na praça Lauro Muller é possível observar a mudança busca da vegetação presente no espaço, e consequentemente a incidência de luz presente nesse ambiente, em contrapartida, a praça continua tendo um ponto central de atração, conforme pode ser observado na figura 5: 


\section{GAMPI
plural ${ }^{15}$}

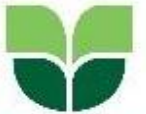 \\ univille}

Figura 5: Comparativo entre a Praça Lauro Muller de 1909 e 2015 - Joinville/SC

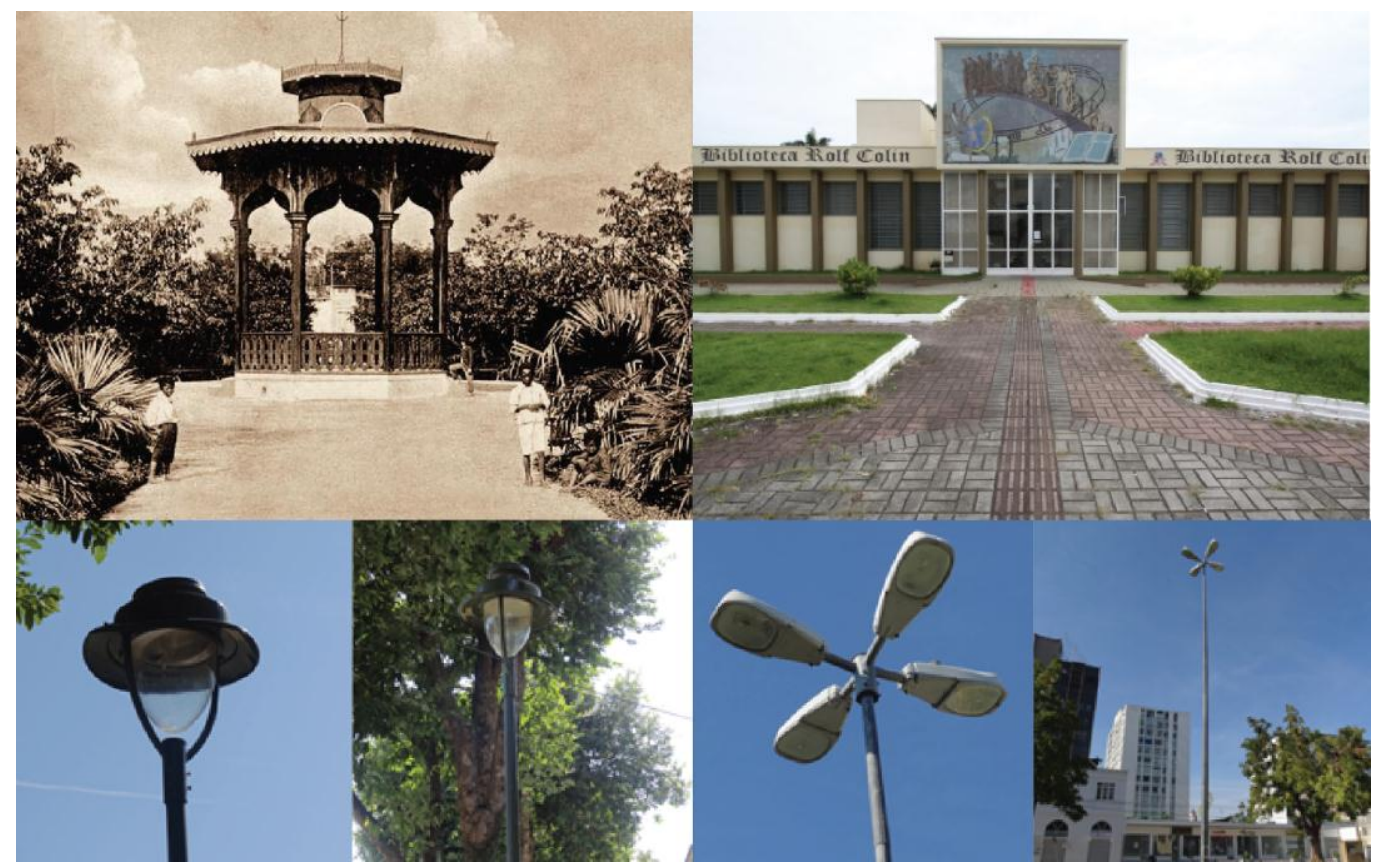

Fonte: Desenvolvido pela autora com base em arquivo pessoal e web.

c) Localizado entre as entradas dos bairros Boa Vista, Guanabara e Fátima, o Parque da Cidade foi inaugurado em 2011 (Consciência com Ciência, 2011, web). O Parque foi projetado com o objetivo de unir o lazer e a preservação ao meio ambiente por meio de atrações como mirante, pista de caminhada, quadras de esporte, playground, palco de eventos, aparelhos de ginástica, lanchonetes e centro de convivência. O atual cenário do parque divide opiniões: de um lado encontramse aqueles que fazem uso da área do parque para praticar esportes e se divertir, do outro aqueles que percebem a falta de arborização, a localização perigosa (devido ao fluxo de veículos) e o auto índice de vandalismo e depredação encontrado no ambiente (A Notícia, 2013). A respeito da iluminação pública encontrada no local, apresenta-se em boas condições, sendo principalmente composta pelas mesmas luminárias encontrada na Praça Nereu Ramos e fazendo uso de luz branca para melhor sensação de segurança da comunidade. Na figura 6 é possível observar as imagens coletadas no ambiente de estudo: 


\section{GAMPI
plural ${ }^{15}$}

Figura 6: Análise das luminárias públicas do Parque da Cidade - Joinville/SC

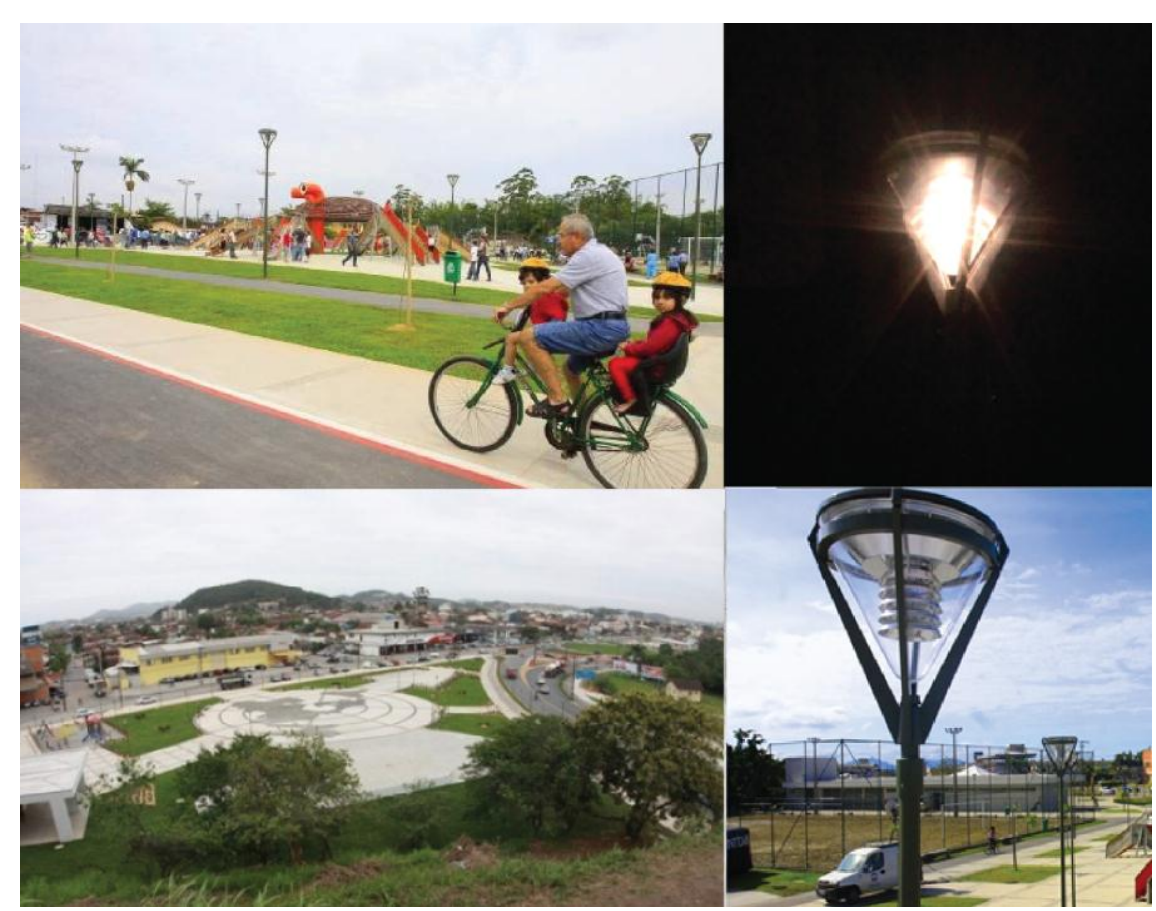

Fonte: Desenvolvido pela autora com base em arquivo pessoal.

d) Inaugurado no fim de 2014, na Zona Sul da cidade, o Parque São Francisco é um dos maiores parques da cidade, apresentando cerca de vinte e três mil metros quadrados. O local apresenta atrações para diversos grupos sociais, oferecendo opções de lazer para todas as idades, como quadras de esporte, palco cultural, pista de skate, playground, campo de futebol e mesa de jogos (IPPUJ, sd, web). O espaço foi bem recebido pela população, e possui iluminação adequada para transmitir segurança à população. No ambiente encontra-se apenas um modelo de luminária pública, trazendo uniformidade ao ambiente, a não ser pelo holofotes utilizados para iluminar à pista de skate e as quadras de esporte. $\mathrm{O}$ espaço conta com o uso de iluminação branca e amarela, sendo estas utilizadas conforme cada região do parque. Na figura 7 são apresentadas imagens referente a coleta de dados no Parque São Francisco: 


\section{GAMPI
plural ${ }^{15}$}

Figura 7: Análise das luminárias públicas do Parque São Francisco - Joinville/SC

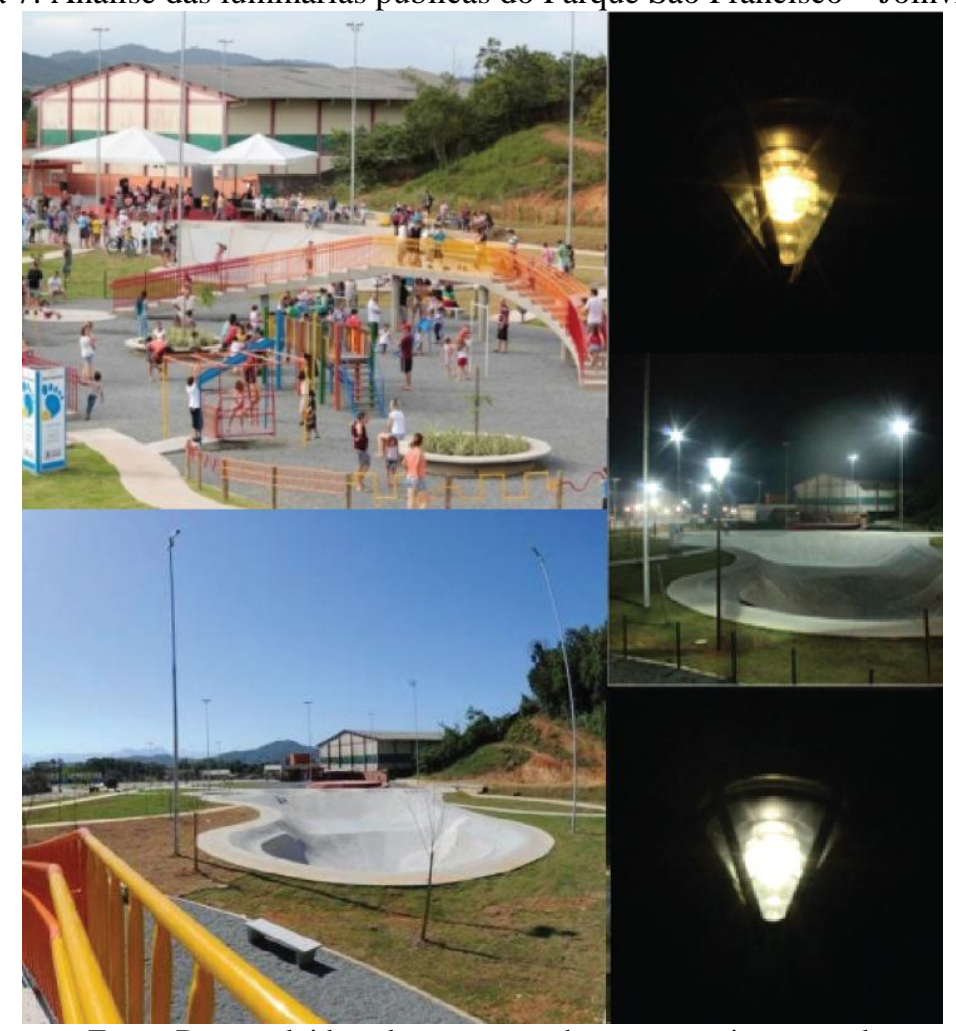

Fonte: Desenvolvido pela autora com base em arquivo pessoal.

A análise dos espaços públicos aqui apresentada foi realizada em dias diversos, no período diurno e noturno, uma vez que o objetivo da análise era desenvolver um levantamento das luminárias utilizadas nestes espaços da cidade de Joinville, sendo que os dias da semana analisados não impactariam no resultado final da pesquisa. As luminárias encontradas nesses espaços transmitem segurança à população de forma geral, porém, o descaso com o espaços centrais da cidade e a falta de utilização transformam estes ambientes hostis. Já os dois parques instalados nos últimos cinco anos transmitem maior segurança e melhor estado de preservação. Dessa maneira, pode-se afirmar que, em razão dos estudos desenvolvidos, a cidade de Joinville apresenta uma identidade nas formas e nas cores das luminárias públicas instaladas em suas praças e parques, ainda que existam algumas variações.

\section{Conclusão}

Tendo em vista à pesquisa aqui apresentada, foi possível perceber que é evidente a constante evolução da iluminação pública e sua contribuição para o desenvolvimento da 

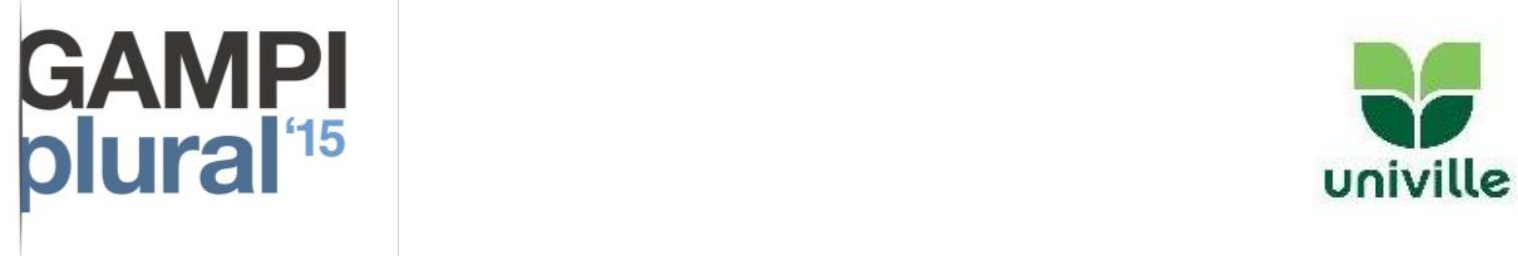

população e das cidades. A pesquisa buscou apresentar de forma breve os impactos que a iluminação pública pode gerar positivamente e negativamente no bem estar da população. Este projeto buscou resultar em um estudo da inserção do design na realidade da IP, procurando proporcionar melhorias ao desenvolvimento da mesma. O projeto também visa contribuir com a formação do acadêmico, gerando vínculo com a pós-graduação. 


\section{GAMPI plural 15}

\section{Referências}

A NOTICIA. Parque da cidade em Joinville completa dois anos. ClicRBS. 2013. Disponível em <http://anoticia.clicrbs.com.br/sc/noticia/2013/11/parque-da-cidade-emjoinville-completa -dois-anos-4324052.html> Acesso em julho de 2015. Acesso em julho de 2015.

AVER, Ana. A relação Iluminação Pública e Criminalidade. Revista Especialize, 2013. Disponível em http://www.ipog.edu.br/revista-ipog/download/a-relacao-iluminacao-publicae-criminalidade Acesso em abril de 2015

CANDURA, Paulo. GODOY, Plínio. Iluminação Urbana: Conceitos e Análises. São Paulo, VJ Marketing Institucional Ltda, 2009.

CONSCIENCIA com Ciência. Inauguração do Parque da Cidade em Joinville - SC. Consciência com Ciência. 2011. Disponível em <http://www.conscienciacomciencia. com.br/2011/11/05/inauguracao-do-parque-da-cidade-em-joinville-sc/> Acesso em julho de 2015 .

ELETROBRÁS Procel. Iluminacao Eficiente: Iniciativas da Eletrobras Procel e Parceiros / Organizadores:Luiz Eduardo Menandro de Vasconcellos e Marcos Alexandre Couto Limberger. - Rio de Janeiro : Eletrobras/ Procel, 2013.

FERNANDES, Wilson. COELHO, Marcel Serra. CAIRES, Tarcísio. O impacto ambiental da poluição luminosa. Disponível em <http://www.amda.org.br/imgs/up/Artigo_01.pdf>

FERREIRA, Milton Martins. A Evolução da Iluminação na Cidade do Rio de Janeiro: contribuições tecnológicas. Rio de Janeiro: Synergia: Light, 2009.

GEHL, Jan. Cidades para pessoas. $1^{\text {a }}$ ed. São Paulo. Editora Perspectiva, 2013.

IPPUJ. Parque São Francisco. Sd. Web. Disponível em <https://ippuj.joinville.sc. gov.br/conteudo/14-Parque+S\%C3\%A3o+Francisco.html> Acesso em julho de 2015.

LIMA, Maria Cristina Dias dos Reis. Um jardim para Joinville. ND Online. 2014. Disponível em <http://ndonline.com.br/joinville/colunas/memoria/156658-um-jardim-parajoinville

.html>

LNA. Identificação e combate à Poluição Luminosa: garantindo o direito à luz das estrelas. Disponível em <http://www.lna.br/lp/index.html> Acesso em julho de 2015. 


\section{GAMPI
plural 15}

LUX Side. Poluição Luminosa - você sabe o que é?. 2012. Disponível em <http://www.luxside.com.br/blog/poluicao-luminosa-voce-sabe-o-que-e/> Acesso em julho de 2015

MACEDO, Catharina C. Análise do Desempenho Térmico e Luminoso de Sistemas de Iluminação Natural que Utilizam a Luz Direta do Sol. 2002. 135 p. Dissertação (Mestrado Engenharia Civil). Curso de Pós -Graduação em Engenharia Civil, Universidade Federal de Santa Catarina, Florianópolis, Santa Catarina.

MARTINS, Juliana. O papel social da luz urbana. O setor Elétrico. 2011, web. Disponível em <http://www.osetoreletrico.com.br/web/component/content/article/57-artigos-e-materias/ 745-o-papel-social-da-luz-urbana.html> Acesso em: 06 de jun. 2015

MASCARÓ, Lúcia. A Iluminação do espaço urbano. 1a ed. Porto Alegre. Ed. Masquatro, 2006.

MUSEU DA LÂMPADA, web. O fogo: A descoberta que revolucionou a vida humana. Disponível em <http://www.museudalampada.com/\#!o-fogo/c1fhw> Acesso em maio de 2015.

NOSSA Joinville. Joinville 160 anos. Disponível em <http://www.nossajoinville.com.br/ 160anos/> Acesso em julho de 2015

OLIVEIRA, Adilson de. A descoberta que mudou a humanidade. Ciência Hoje. 2010. Disponível em <http://cienciahoje.uol.com.br/colunas/fisica-sem-misterio/a-descoberta-quemudou-a-humanidade> Acesso em maio de 2015

php/ilumincao_publica>

ROSITO, Luciano Haas. A origem da iluminação pública no Brasil. O Setor Elétrico. Edição 36. 2009. Disponível em < http://www.osetoreletrico.com.br/web/component/content/ article/45-desenvolvimento-da-iluminacao-publica-no-brasil/946-capitulo-i-as-origens-dailuminacao-publica-no-brasil.html> Acesso em junho de 2015

SANTANA, Rosa Maria Bomfim. Iluminação pública: uma abordagem gerencial. 2010. 94 p. Dissertação (Mestrado em Regulação da Indústria de Energia) Universidade Salvador. Programa de Pós-graduação em Engenharia Mestrado em Regulação da Indústria de Energia. Salvador, Bahia.

SANTOS, Eduardo Ribeiro dos. A iluminação pública como elemento de composição da paisagem urbana. 109 f. Dissertação - Universidade Federal do Rio Grande do Sul, 2005 .

SECRETARIA DE ENERGIA DO ESTADO DE SÃO PAULO. Cartilha de Iluminação Pública: Guia do Gestor. 2013. Disponível em <http://www.energia.sp.gov.br/portal. 

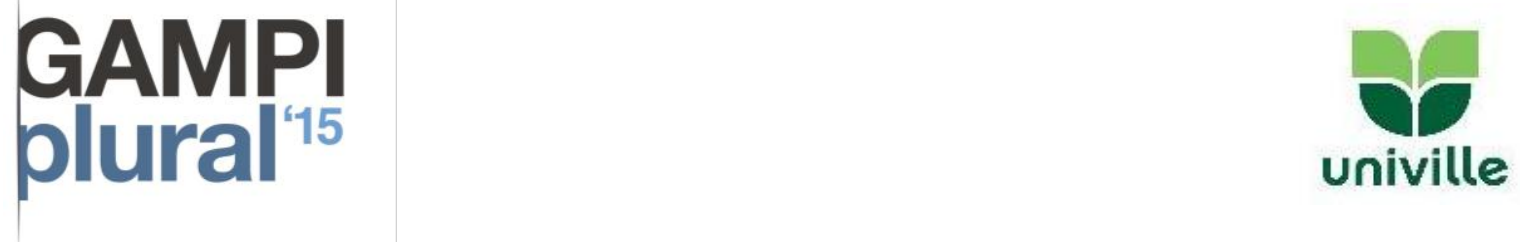

SOUSA, Rainer. Período Paleolítico. Brasil Escola, sd, web. Disponível em <http://www.brasilescola.com/historiag/paleolitico.htm> Acesso em maio de 2015. 